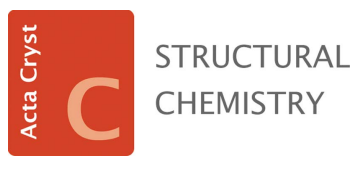

ISSN 2053-2296
Keywords: book review; electrochemistry.
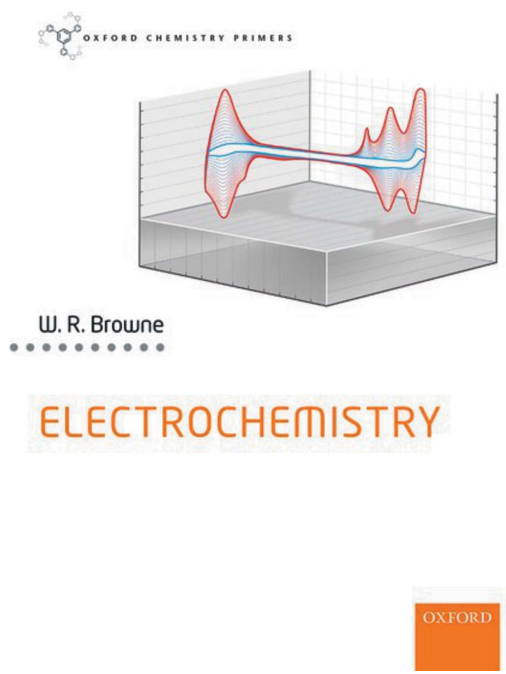

(C) 2019 International Union of Crystallography

\section{Electrochemistry. By Wesley R. Browne. Oxford University Press, 2018. Paperback, Pp. 152. Price GBP 19.99 ISBN 9780198790907}

\author{
Marc Hebrant*
}

Université de Lorraine, CNRS, LCMPE, Nancy, France. *Correspondence e-mail: marc.hebrant@univ-lorraine.fr

The body of the text of this book is 120 pages and covers all aspects of electrochemistry, from the most basic aspects (electrode, redox and potential) to Tafel curves, dynamic electrochemistry (voltammetry), corrosion, batteries, fuel cells, impedance spectroscopy etc.

As an introduction, the author starts with the basic concept of the electric circuit, and in some examples equivalent circuits are given. At the end of each chapter there are a few exercises, easy to solve for the careful reader, encouraging others to delve back into the chapter to find the solution.

To be able to address all these points in such a short book, the author has made considerable effort to summarize the text. The basic fundamental science viewpoint is the right one, especially as the book is part of the series 'Oxford Chemistry Primers' directed at undergraduate students. Only physicochemical phenomena are described and discussed. No room is left for technical aspects and analytical chemistry applications, and only a few real results are given for illustration purposes.

Despite the large number of available books dealing with electrochemistry, having a short book will allow nonspecialist scientists to have a complete view of the field.

Moreover, even for those already having a knowledge of electrochemistry, re-examining the order in which the aspects of the subject are usually taught may be interesting; for instance, batteries and electrical impedance are not that often in the same chapter, and starting from the electric circuit is also rather unusual.

The concept is thus a good one and the book could be of great help for many students or scientists wishing to have an overview of the field, who can then go deeper into a particular subject by reading one of the more specialized books available.

It is therefore all the more regrettable that many faults, errors and typographical errors spoil the impact and interest of this book, especially taking into account that it is directed at undergraduate students. A small sample of the faults that may be found is given below, but it is not an exhaustive list.

Heterogeneous notation (none of them following the IUPAC recommendation) may be found:

- the sign used for a reaction or a half reaction is variously a double arrow, a simple arrow or two opposite arrows;

- depending on the chapter, $\Delta G, \Delta G^{0}$ and $\Delta_{\mathrm{r}} G^{0}$ may be found for the same concept;

- the same item is called $E^{0}, E_{1 / 2}$ and $E_{1 / 2}^{0}$, this point is not only formal: it mixes experimental data in dynamic electrochemistry $\left(E_{1 / 2}\right)$ and thermodynamic data $\left(E^{0}\right)$;

- there is some mixing between $E_{\text {cell }}$ and the $E$ of the electrode in Chapter 3; this is again not only a formal problem.

Many editing problems resulting from mistyping:

- some errors in the mass balance in chemical equations;

- non-existent species $\left[\mathrm{I}_{4}, \mathrm{O}_{2}^{-}(\mathrm{g}) \ldots\right]$;

- sentences strictly without meaning ['The Latimer (left) and Frost (right) diagrams for copper also show thio' on p. 26 in which there is no diagram on the right...];

- sometimes figures are numbered, equations are never numbered and sometimes they are on several lines with paragraph numbering randomly appearing alongside the equations (p. 27). 


\section{Errors:}

- Nafion is not a modified polystyrene (p. 36), the electron is not known to be in solution but rather in an electric conductor (p. 51);

- writing a constant potential for the couple $\mathrm{Fe}^{3+} / \mathrm{Fe}^{2+}$ to illustrate the dependency of potential toward $\mathrm{pH}$ is not correct: depending on the iron concentration in solution, $\mathrm{Fe}(\mathrm{OH})_{3}(\mathrm{~s})$ may be formed at $\mathrm{pH}>1.5$ and $\mathrm{Fe}(\mathrm{OH})_{2}(\mathrm{~s})$ at $\mathrm{pH}>6$, both species greatly influence the potential of this couple. These are only a few examples of the mistakes and faults and clearly, despite the interesting concept and the very attractive price, this book cannot be recommended. 